AperTO - Archivio Istituzionale Open Access dell'Università di Torino

\title{
Restrictions in word-formation
}

\section{This is a pre print version of the following article:}

Original Citation:

\section{Availability:}

This version is available http://hdl.handle.net/2318/1532450

since 2015-12-11T17:26:56Z

Publisher:

Mouton de Gruyter

Terms of use:

Open Access

Anyone can freely access the full text of works made available as "Open Access". Works made available under a Creative Commons license can be used according to the terms and conditions of said license. Use of all other works requires consent of the right holder (author or publisher) if not exempted from copyright protection by the applicable law. 
Schultink, Henk

1961 Produktiviteit als morfologisch fenomeen. Forum der Letteren 2: 110-125.

Siegel, Dorothy

1977 The Adjacency Condition and the theory of morphology. In: Mark J. Stein (ed.), Proceedings of the Eighth Annual Meeting of the North East Linguistic Society, 189-197. Amherst, Mass.: North East Linguistic Society.

Štichauer, Pavel

2009 La produttività morfologica in diacronia: $i$ suffissi -mento, -zione $e$-gione in italiano antico dal Duecento al Cinquecento. Praha: Karolinum.

Thornton, Anna M.

1998 Quali suffissi nel "Vocabolario di Base"? In: Federico Albano Leoni, Daniele Gambarara, Stefano Gensini, Franco Lo Piparo and Raffaele Simone (eds.), Ai limiti del linguaggio, 385-397. Roma/Bari: Laterza.

Vincent, Nigel

1988 Italian. In: Martin Harris and Nigel Vincent (eds.), The Romance Languages, 279-313. London: Routledge.

Wellmann, Hans

1975 Deutsche Wortbildung. Typen und Tendenzen in der Gegenwartssprache. 2. Hauptteil: Das Substantiv. Düsseldorf: Schwann.

Williams, Edwin

1981 On the notions 'lexically related' and 'head of a word'. Linguistic Inquiry 12: 245-274. Wurzel, Wolfgang U.

1984 Flexionsmorphologie und Natürlichkeit. Berlin: Akademie Verlag.

Livio Gaeta, Turin (Italy) and Davide Ricca, Turin (Italy)

\section{Restrictions in word-formation}

1. Introduction

2. Constraints on word-formation rules

3. Domain-specific restrictions

4. References

\section{Abstract}

The main factors taken to be responsible for constraining or restricting the application of word-formation rules are surveyed. On the one hand, constraints of a general nature will be discussed which may be due to several distinct reasons ranging from our concrete cognitive abilities to different views of approaching word-formation from a theoretical point of view. On the other, a typology of more specific restrictions will be provided which result from the interaction of the different levels of the linguistic analysis. 


\section{Introduction}

Word-formation rules (WFRs) typically undergo a number of general constraints or more specific restrictions conditioning or limiting their productivity, the latter intended in a broad sense as the possibility of applying to lexical bases serving as an input (see the article 48 on productivity for a survey). Rainer (2005a: 335) observes that the question of restrictions only arises for productive WFRs, for which the application domain has to be defined intensionally, i.e. by indicating one or more features that any potential base must or should possess as well as additional factors from outside the pattern itself that may be relevant. For unproductive rules the domain is generally described extensionally by enumerating the set of bases to which the rule applies. However, this does not exclude that intensionally defined features may also synthetically summarize the properties shared by the enumerated bases, especially when the latter are quite numerous. What is more, productivity is likely to be a gradient notion to the effect that in some cases a very low degree of productivity approximates unproductivity.

The question of the restrictions on WFRs has been the object of wide investigations ever since, and recent surveys can be found in Bauer (2005) and Rainer (2000, 2005a). As a matter of fact, a big part of the research carried out in word-formation focuses on the restrictions displayed by WFRs. They can be approached adopting two different, although interwoven, perspectives: theory-driven restrictions or constraints of a general nature, and specific restrictions empirically resulting from the analysis of single language-specific patterns. The latter also come from the interaction of morphology with the other components of the language.

In what follows, a survey of the different aspects of the question will be offered, (i) starting with different views of looking at constraints and restrictions and subsequently (ii) developing a typology of restrictions resulting from the interaction of the different levels of the linguistic analysis. In this regard, it must be observed that constraints are usually considered to be those absolute limitations on WFRs which are of a rather general nature while restrictions have a more reduced scope (cf. Rainer 2005a). On the other hand, in the shade of Optimality Theory constraints can also be taken to be violable, much more limited in scope and hierarchically ordered (cf. Bauer 2001: 126). However, the literature is not always consistent with these distinctions; in this article I will follow Rainer's distinction and generally speak of constraints with regard to general limits on WFRs which are independent of the particular linguistic level considered while restrictions are held to be of a more reduced scope.

\section{Constraints on WFRs}

Generally, there are two possible ways of looking at the question of constraints on WFRs: the first view adopts a top-down perspective, according to which there are constraints due to the format of the grammar and more in general of the language faculty; this view is accordingly competence-oriented. The opposite view is performance-oriented and treats the constraints as resulting in a bottom-up fashion from the way in which our language faculty concretely treats lexical items when they are processed by our cognitive equipment. From the interplay of these two opposite views four possible families of 
constraints can be identified, which also reflect the historical trend from more competence-oriented approaches typical of the early models of word-formation to the more performance-oriented views characterizing more recent research supported by the use of large electronic corpora.

\subsection{Constraints relating to the format of the WFRs}

A first type of constraints directly depends on how WFRs are generally conceived. In this regard, a question which has been discussed at length concerns the input of WFRs, whether they select as a base a possible or an actual word or rather an abstract morpheme. In a nutshell, while nothing seems to hinge a priori on whether a word is possible or actual, i.e. stabilized or entrenched in our mental lexicon, the question of word- or morpheme-based WFRs is much thornier. As to the first point, it can be easily shown that possible but unattested words can constitute the input of WFRs, as in to decaffeinate which presupposes the unattested ${ }^{\circ}$ to caffeinate. On the other hand, WFRs may be sensitive to the actual status of the base, as in the cases of paradigmatic word-formation pointed out by Rainer (1993: 29) in which a complex word is formed on the basis of another complex word as in the German compound Volkszählung 'population census, lit. population count' $\rightarrow$ Volkszähler 'person carrying out the census', which can only be interpreted with regard to the idiosyncratic meaning of the base. Thus, a conceivable form ??Volksberechner is odd because no base ??Volksberechnung 'population count' occurs. Furthermore, bases that are stabilized in the lexicon and give rise to instances of paradigmatic word-formation may also be larger than one word, as in baroque flute $\rightarrow$ baroque flutist, while ??wooden flutist is odd because wooden flute is not stabilized in the lexicon (cf. Spencer 1988). This latter example calls into play another family of constraints which aim at limiting the access of syntactic patterns and rules below the word level and go under various names such as 'lexical integrity principle', 'no phrase constraint', etc. (see Gaeta 2006 for a recent survey).

As to the second point, Aronoff (1976) launched the slogan of a word-based wordformation intending that the input of WFRs cannot consist of (bound) morphemes but rather of full lexemes (possibly deprived of their inflectional endings). This is motivated by word pairs like aggression/aggressive which are not to be derived from a bound stem *aggress- but rather form a series of derivatives Xion/Xive, in which the adjective is formed on the basis of the action noun. Substantive evidence in support of this analysis is provided among others by those cases in which an available verb stem cannot be the base of the adjective which is rather formed on the action noun: induction $\rightarrow$ inductive in spite of to induce (cf. Aronoff 1976: 28-30). However, although words intended as lexemes are undoubtedly the prototypical input of WFRs, the restriction on bound stems cannot be universal as is shown on the one hand by bound stems like log-occurring in logic, logistics, etc. On the other, for languages of the polysynthetic or strongly fusional (including the introflecting) type, the concept of lexeme may be much more difficult to define. For instance, in Montagnais, an Algic language spoken in Canada, a strictly morpheme-based approach has been defended (cf. Drapeau 1980). However, morphological templates characterizing non-concatenative processes might be more easily treated in a word-based fashion rather than in a morpheme-based framework which can only 
accommodate a linear concatenation of morphemes intended as atomic units. For instance, in Hindi/Urdu the anticausative verb form is claimed to be straightforwardly obtained by shortening the root vowel: $\left[\mathrm{XV}_{1} \mathrm{~V}_{1}\right]_{\mathrm{V}}$ 'A causes $\mathrm{B}$ to happen' $\leftrightarrow\left[\mathrm{XV}_{1}\right]_{\mathrm{V}}$ 'B happens', as in maar-/mar- 'to kill/die' (cf. Haspelmath 2002: 49).

This question has gained more relevance in recent times after Aronoff's (1994) "morphomic" turn especially from the perspective of a realizational approach to inflectional morphology as suggested by Stump (2001: 2). This view has repercussions for WFRs that manifest themselves in a general tendency towards the maximization of base allomorphy with respect to affix allomorphy (cf. Loporcaro 2012 for a discussion with regard to inflectional morphology). The base allomorphy is accordingly dealt with in terms of different "morphomes", i.e. concrete formats of a certain lexeme, selected by the affix. In this way, a bias arises towards favoring as input to WFRs existing morphomes, while abstract, underspecified morphemes like stems which increase affix allomorphy are taken to be costly. In brief, the problem is how to deal with cases which allow different interpretations going back to different input bases. This also implies a different format for the affix. For instance, there are at least two different allomorphs for the Italian suffix forming agent or instrument nouns found in stampare 'to print' $\rightarrow$ stampatore 'printer' or udire 'to hear' $\rightarrow$ uditore 'hearer' in contrast with aggredire 'to attack' $\rightarrow$ aggressore 'mugger', distribuire 'to distribute' $\rightarrow$ distributore 'distributor', etc. (see the article 45 on paradigmatically determined allomorphy: the "participial stem" from Latin to Italian). The latter derivatives select as base the Latinate perfect participle which does not match the actual past participle (cf. *aggresso vs. aggredito, *distributo vs. distribuito). On the other hand, the former may be either analyzed as formed by -tore plus the so-called verbal stem (formed in turn by the root plus the thematic vowel: stampa-tore), or by -ore plus the stem of the past participle (cf. stampat-ore). The latter analysis presents the advantage of minimizing the suffix allomorphy at the expense of the base allomorphy for which two distinct morphomes have to be assumed. In addition, it also accounts for derivatives like diffondere 'to diffuse' $\rightarrow$ diffusore 'diffuser' based on the Italian past participle diffuso. However, this choice leaves unexplained on the one hand those cases which require as a base the verbal stem instead of the past participle as scoprire 'to discover' $\rightarrow$ scopritore 'discoverer' (cf. the past participle scoperto), and on the other new formations which are based neither on the Latin nor on the Italian participle but are rather formed from the parallel action nouns suffixed with -ione like estorcere 'to extort' $\rightarrow$ estorsore 'blackmailer' / estorsione 'extortion' (cf. the Latin and Italian past participles extortus/estorto, see Rainer 2001), possibly under the influence of Neo-Latin patterns (see the article 88 on word-formation in Neo-Latin).

A second type of constraints on the format of WFRs focuses on their possible input or output, and maintains that any WFR should be limited to one single word category in input (Unitary Base Hypothesis, UBH, cf. Aronoff 1976: 47) or in output (Unitary Output Hypothesis, UOH, cf. Scalise 1984: 137). As for the UBH, it has been pointed out that practically any combination of features such as $[ \pm \mathrm{N}],[ \pm \mathrm{V}]$ and the like has been suggested, which means that "by choosing the appropriate feature system the UBH can be immunized against refutation" (Plag 1999: 48). Furthermore, the process of base selection is most likely guided by rule-specific semantic principles (cf. Plag 1998: 237) rather than by purely abstract features. Finally, WFRs are often sensitive to well-defined lexical sub-domains on the basis of a unitary meaning of the process (cf. Plank 1981: 43-65, Rainer 2005b). At any rate, in many cases the decision of considering two deriva- 
tives from different bases (like for instance the denominal fashion-able and the deverbal accept-able) as related to the same or to a different WFR depends on how much we look with favor at the occurrence of affixal homonymy or we rather prefer the assumption of rules of semantic extension as those discussed in the article 72 on agent and instrument nouns.

While the UBH has been discussed at length, the UOH has enjoyed much less discussion and has been, to a large extent, taken for granted. In principle, the $\mathrm{UOH}$ opens two different perspectives depending on whether the formal or the semantic aspect of the WFR is in focus. From the formal perspective, the UOH is strictly connected to the degree of allomorphy one is willing to tolerate before considering two affixes as distinct. For instance, in the Italian case discussed above one might be tempted to postulate two different WFRs, a first one selecting a suffix -tore and a second one selecting -ore. In virtue of their identical meaning, however, this choice is likely to be inadequate. On the other hand, nobody would postulate a unitary WFR for two utterly different affixes sharing the same meaning such as -ant in to inhabit $\rightarrow$ inhabitant and -er in to sleep $\rightarrow$ sleeper. In other words, suppletion is generally admitted for lexical bases (e.g., the French pair eau 'water' / hydr-ique 'hydric', cf. Schwarze 1970) but much less so for derivational affixes. Notice that this does not hold for inflectional rules (e.g., the Hungarian second person singular suffix of the indefinite present takes the form -ol after sibilants or affricates and -(a)sz elsewhere, cf. Carstairs 1988: 70), probably because of the stronger paradigmatic force displayed by inflection versus that of word-formation.

Scalise (1984) suggests that the UOH might be valid only for the formal aspect of WFRs, not for their semantic aspect. However, that the question is much more complex is shown by the Italian suffix -ino which gives rise to several different sorts of derivatives: mare 'sea' $\rightarrow$ mar-ino 'marine', tavolo 'table' $\rightarrow$ tavol-ino 'table-DIM', bocca 'mouth' $\rightarrow$ bocch-ino 'mouthpiece' and stagno 'tin' $\rightarrow$ stagn-ino 'tinker'. The first case can be explained away as an instance of affixal homonymy because the output word category is clearly different (an adjective vs. a noun), although this criterion is not uncontroversial as the objections raised against the UBH above also apply here. The other three examples are more complicated, because the purely diminutive value found in tavolino can also be traced back in instrument nouns like bocchino that denote little objects, and even the agent nouns like stagnino generally refer to humble, in a way "little" professions. Even worse, these cases are paralleled by deverbal instrument and agent nouns like, respectively, cancellare 'to erase' $\rightarrow$ cancellino 'eraser' and spazzare 'to sweep' $\rightarrow$ spazz-ino 'street sweeper', which display exactly the same properties. It is not easy to decide whether all of this should be assigned to the same or to different WFRs. Similar to what we observed above for the UBH, the decision depends on the likelihood of assuming rules of semantic extension; as an alternative, one might also think of a relationship in terms of family resemblance of a Wittgensteinian kind among the several nominal types that have in any case to be kept apart from the adjectival homonym (see the article 60 on schemata and semantic roles in word-formation).

Finally, a further constraint generally assumed is the open-class base hypothesis which requires that only major lexical classes can be input of WFRs, namely nouns, verbs, adjectives and adverbs. This excludes that, for instance, adpositions and pronouns be involved in WFRs, which forces an analysis of certain patterns like German hinauf 'thereon', darunter 'there:below', etc. as resulting from a process different from wordformation proper. Moreover, it is not expected to find cases like Spanish le 'her' $\rightarrow$ 
leismo 'use of the form le for direct objects', in which a pronoun serves as the input of a WFR. However, one can conclude that the major word classes represent the most common or prototypical input of WFRs, although this restriction probably has to be related to the main function of vocabulary enrichment typical of word-formation. In this light, words belonging to the minor word classes usually display grammatical meaning which is only in restricted cases salient enough to be used in word-formation as shown by the Spanish example mentioned above or by numerals (see the article 84 on denumeral categories).

\subsection{Constraints relating to general properties of the grammar}

In the light of its general value, the last constraint might also be treated in this section, which discusses constraints depending on general properties usually held to shape our language faculty. One such property is expressed by the compositionality or Frege's principle, because the German logician Gottlob Frege is generally credited for its first modern formulation (but see Klos 2011): it requires that the meaning of a complex word resulting from a WFR be a function of the meaning of the rule and the base. Against Frege's principle, clear cases of analogical formations have been mentioned which require a holistic reference to another complex word like the German compound Doktormutter 'female thesis supervisor' with regard to its male counterpart Doktorvater. In general, a holistic approach has to be assumed when affix substitution occurs like the Italian verb svitare 'to unscrew' which can only be interpreted by making reference to a previous avvitare 'to screw' (cf. *vitare), or with instances of bracketing paradoxes like multiconfessional which is formally derived by prefixation [[multi]confessional] but semantically requires the analysis [[multiconfession $]$ al $]$. At any rate, this anisomorphism between form and meaning can be treated in terms of the paradigmatic relations mentioned above and is not substantially different from a strictly compositional approach on condition that the lexical status of the pattern is duly taken into account. In other terms, the compositionality and the holistic approach simply reflect the two different routes followed by the speakers when they access complex words, namely decomposition or full lexical access (cf. Baayen and Schreuder 2003 for a recent survey).

Further constraints focus on the limits imposed on WFRs which result from the interaction with other components of the language. In particular, general trends favoring haplology have been observed for many languages, which block the application of a WFR if a phonological string is replicated by the addition of an affix. For instance, the Italian deanthroponymic suffix -iano is normally blocked when the base ends with the same string: Gadda $\rightarrow$ gaddiano, but Flaiano $\rightarrow$ ??flaianiano. In spite of the apparently universal character of this tendency towards the avoidance of cacophonic repetitions, formulating a general rule is not an easy task (see section 3.6.).

A second more debated case concerns recursion which is normally widely present in syntax, but much less so in word-formation. Recursion seems to be generally possible in compounding (although languages may differ as to its extent) but much more restricted in affixation. In contrast to syntactic recursion, recursion in word-formation is strongly limited by two aspects: on the one hand, WFRs often are property-changing, which prevents their immediate reapplication to the output. On the other, the systematic reappli- 
cation of WFRs leads to long chains of morphemes which may present problems from the viewpoint of their processing, especially when property-changing affixes occur as, for instance, in organizationalization. When the last two factors do not intervene, recursion can be generally observed as in the case of the Italian evaluatives casa 'house' $\rightarrow$ cas-etta 'small house' $\rightarrow$ cas-ett-ina 'small small house'. Finally, while the reapplication of two identical suffixes seems quite rare (again with the remarkable exception of evaluative suffixes as in the colloquial Spanish examples ahora 'now' $\rightarrow$ ahor-it-ita 'right now', amigo 'friend' $\rightarrow$ amig-az-azo 'close friend', cf. Rainer 1993: 108), prefixes are in general more liberal, probably because they are mostly not property-changing, as in re-rewrite and the like.

Finally, general constraints can also come from the interaction with factors external to the language faculty but of high relevance with regard to the function of lexical enrichment generally assigned to word-formation. A first constraint has to do with the demand of new words which is of greatest importance for those WFRs which are more connected with the naming function rather than with other functions carried out by WFRs like the mere transcategorization. This is clearly the case with WFRs forming agent or instrument nouns which presuppose the existence of a certain profession or device. This fact contributes to a large extent to shape our lexicon as the result of our cultural historical development and to motivate the varied degree of acceptability of certain formations which synchronically lack a referent like Spanish arzobispa 'lit. archbishop (fem.)', calienta-ojos 'lit. eyes-warmer', etc. (cf. Rainer 1993: 113). The possible unacceptability of these formations is likely to be guided not by grammatical - i.e. competence-oriented - principles, but rather by performance-oriented conditions, also connected with our world knowledge (see section 3.6. and article 54 on dissimilatory phenomena in French word-formation).

Similar observations also hold for a constraint such as neophobia which has been invoked to account for the low acceptability of new formations simply because they are unusual words (cf. Gyurko 1971 on Spanish). This is especially the case with neologisms which are launched in creative writing (intending on the one hand literary works and on the other products which involve the conscious manipulation of language like advertisements). What appears more acceptable in certain contexts allowing for more creativity may be rejected in contexts requiring a stricter subscription to a shared norm.

\subsection{Constraints relating to the particular format of the grammar}

While the former constraints can be considered to be theory-independent and therefore universal, the constraints discussed in this section are strictly related to a certain format attributed to the grammar. For instance, in the late seventies a number of locality conditions were formulated which aimed to restrict the number of features visible to a certain WFR in a given domain like Siegel's (1977) 'adjacency principle', Williams' (1981) 'atom condition', or Kiparsky's (1982) ‘bracket erasure convention' (cf. Plag 1999: 4546 for a brief survey). As repeatedly emphasized in the literature, these constraints were flawed by serious problems, due among others to an insufficient empirical basis underlying their formulation. At any rate, when the interest in generative grammar sailed towards theoretical shores different from conditions on rules, these constraints were simply aban- 
doned. A similar problem concerns the binary branching hypothesis (cf. Scalise 1984: 146-151), which - far from being universal - is systematically falsified by coordinative compounds like German-French-English (corporation) and therefore best to be viewed as consequence of the semantics of determinative compounds rather than as the result of a formal constraint on the grammar format (cf. Barri 1977).

Stratal conditions on WFRs deserve a partially different discussion. The latter were originally formulated to account for the well-known fact that the WFRs may be sensitive to certain sets of lexical items (lexical strata, cf. Saciuk 1969) characterized for instance in etymological terms (e.g., 'of Latin origin'). This idea was further expanded by assuming at least two different and serially ordered derivational strata or levels to which the affixes belong (cf. Siegel 1979). Accordingly, the properties shared by different groups of affixes result from the specific level assigned to them and need not be specified for the single WFRs. Against the stratal view it has been generally objected that it is largely impossible to account for the severe restrictions on the combinability of the affixes especially when they belong to the same level (cf. Fabb 1988). Furthermore, in several cases affixes have to be assigned to more than one stratum in order to account for their selective and allomorphic properties. This weakens the stratal approach considerably. On the other hand, there are surely languages in which the lexicon is sharply compartmentalized into separate strata (see the article 183 on Maltese), displaying robustly different properties. For instance, in German the native WFRs do not generally produce prosodic changes on the bases, while the non-native WFRs are largely characterized by stress shifts: Wissenschaft 'science' $\rightarrow$ Wissenschaftler 'scientist' vs. Térror 'terror' $\rightarrow$ Terrorist 'terrorist'.

An orthogonal question relates to the source of the selective properties, whether they must be sought in the WFRs, i.e. in the affixes, as generally assumed by those who support a stratal approach, or in the bases, as maintained by Plag (1999: 67-76) who defends a generalized base-driven approach. Accordingly, the selective correlation between the German non-native noun-forming suffix -ität and the non-native adjectival bases as in banal 'banal' $\rightarrow$ Banalität 'banality' is taken to be driven by the latter. This approach is more economic than the former because it does not require us to assume a complex mechanism of rule-by-rule blocking to account for the oddness of the conceivable form *Banalheit. Furthermore, it also accounts for cases in which the non-native suffix is selected by native bases like schwul 'gay, queer' $\rightarrow$ Schwulität 'embarrassing situation', which violate a rigid stratal view (see section 2.4.). However, doublets of derivatives from the same base should in principle be excluded, but exceptions of this kind are not uncommon, as shown by cases like absurd 'absurd' $\rightarrow$ Absurdität/Absurdheit 'absurdity', naiv 'ingenuous' $\rightarrow$ Naivität/Naivheit 'ingenuity', etc.

\subsection{Constraints depending on lexical accessibility}

The problems relating to the lexical strata and their ordering have been approached recently from a completely different perspective, which has been termed by Plag complexity-based ordering. This refers to the general properties displayed by the lexical items when they are processed by our cognitive capacities. In particular, Hay (2000, 2002) suggests that more easily parsable affixes should be normally less restricted than 
less easily parsable ones and accordingly should occur more externally. On the other hand, words containing less easily parsable affixes are more likely to be directly accessed as units entrenched in our mental lexicon. The ease of parsability, or its counterpart lexical entrenchment, are influenced by factors like frequency, especially relative frequency, i.e. the frequency of a derivative with respect to its base, and phonotactics. The latter refers to the occurrence of less frequent sound clusters resulting from the combination of two morphemes which are a better cue for detecting and parsing a morphological boundary than sound clusters occurring frequently inside morphemes. Relying on these parameters, Hay provides a hierarchy expressing the combinability force of the single affixes with regard to the base: affixes scoring higher in terms of relative frequency and phonotactics are likely to be placed closer to the base. In spite of the attractiveness of this entirely performance-oriented approach, it is empirically insufficient because of the fact that specific selectional restrictions are also required to account for the number of impossible combinations normally observed (cf. Hay and Plag 2004).

A second family of constraints relating to lexical accessibility goes under the broad label of blocking although substantially different things have to be understood here. First of all, one must distinguish between homonymy and synonymy blocking: the first type has been suggested to account for the non-occurrence of denominal verbs like spring $\rightarrow$ $*$ to spring, fall $\rightarrow *$ to fall parallel to summer $\rightarrow$ to summer, winter $\rightarrow$ to winter because of the mere presence in our mental lexicon of the corresponding homophonous verbs. However, the non-occurrence - at least in British English, see Bauer (1983: 97) - of *to autumn in the absence of any homonymous verb casts doubt on the reliability of this explanation. More in general, "this approach fails to expound why language tolerates innumerable ambiguities, but should avoid this particular one" (Plag 1999: 50).

Much more relevance has been attributed to the second type of synonymy blocking. Two cases have to be distinguished: word or (perhaps slightly emphatically) Paul's blocking, in which the occurrence of one synonymic lexeme in our mental lexicon is made responsible for the non-occurrence of a possible derivative as in the classic example of thief blocking the formation of ??stealer. In this case, which is a true instance of lexical blocking as already envisaged by Hermann Paul (1896: 704), the accessibility of the established word is of crucial relevance: as argued by Rainer (1988: 163), the blocking force of the established word is a direct function of its frequency and of the productivity of the intervening WFR. On the other hand, the blocked word is not really illformed, but a potentially usable word - and indeed often attested - provided that for some reason a speaker fails to retrieve the blocking established word and/or is in search of a particular meaning effect as in scene-stealer (cf. Rainer 2012). Notice that potential words like ??stealer are different from possible words like ${ }^{\circ}$ to caffeinate seen in section 2.1 also because they are usually inert to further derivation as shown by the impossibility of ??stealerless with regard to pairs like leader $\rightarrow$ leaderless, teacher $\rightarrow$ teacherless, etc., while ${ }^{\circ}$ caffeination is a possible word exactly like its base. In this regard, Rainer (2005a: 337) formulates a Possible Base Constraint according to which bases of WFRs must be possible words while merely potential words are excluded.

The second case is more complicated and can be referred to as rule or Pāninin's blocking, because the non-occurrence of a derivative is accounted for by the fact that a synonymous pattern takes precedence provided that both patterns are productive. This reminds us very closely of the so-called Pạnini's or elsewhere principle whereby the application of a more specific rule blocks that of a more general one, as already envisaged by the 
Indian grammarian Pāṇini (cf. Kiparsky 1973; for a different view see Giegerich 2001). Rainer (1988) suggests to account in these terms for the lexical domain of the German quality nouns formed on the basis of end-stressed adjectives. The latter select different suffixes in dependence of a set of features restricting in a cumulative way their scope of application. Thus, the suffix -heit normally combines with end-stressed adjectives: gewiss 'sure' $\rightarrow$ Gewissheit 'sureness', ordinär 'vulgar, common' $\rightarrow$ Ordinärheit 'vulgarity', etc., unless they display a learned flavor; in this case they select -ität: binär 'binary' $\rightarrow$ Binarität 'binarity'/??Binärheit, cf. also ??Ordinarität, only possible with a mathematical meaning: 'the property of being a common event'. Finally, if a learned, endstressed adjective ends with the bound stem -phil, it selects the suffix -ie: xenophil 'xenophile' $\rightarrow$ Xenophilie 'xenophilia'/??Xenophilität/??Xenophilheit. Notice that the simple occurrence of an ending/-fil/ does not trigger the application of -ie and the superordinate preference for -ität applies in the light of the learned flavor: monofil 'unifilar' $\rightarrow$ Monofilität 'unifilarity'/??Monofilie/??Monofilheit.

Although they rely on a similar synonymic mechanism, Paul's and Pāṇini's blocking are two completely different phenomena because the former refers to the degree of entrenchment of a word in our mental lexicon which is measurable in frequency terms, while the latter is due to the selective specificity of two rules applying to (portions of) the same set of lexical bases. In fact, Rainer (2005a: 337) observes that Pānini's blocking may also "apply even when no actual blocking word formed according to the rival pattern exists". Furthermore, while a word like ??Xenophilheit can be said to be illformed because of the conditions on the selected base, ??stealer is not ill-formed stricto sensu, as discussed above. At any rate, frequency may also play a role in the case of Pānini's blocking as shown by the occurrence of doublets of derivatives from the same end-stressed adjectives if the latter "have become part of a more colloquial register" (Rainer 2005: 338): debil 'stupid' $\rightarrow$ Debilheit 'stupidity', beside established Debilität, skurril 'droll' $\rightarrow$ Skurrilheit 'drollery', beside established Skurrilität, etc. (see the pairs Absurdität/Absurdheit, etc. mentioned in section 2.3.). Clearly, the property of becoming part of a more colloquial register is also connected with an increase of frequency, which has the effect of relaxing the strict condition on learnedness.

On the other hand, Rainer (1988: 172) has suggested that frequency may interfere in cases of affix rivalry systematically blocking a derivative when a clearly more frequent competitor occurs. This is allegedly the case of the Italian deadjectival nouns formed with the two highly productive suffixes -ismo and -ità, whereby frequent quality nouns selecting -ismo (by dropping the ending -ico of the base) are said to block the possible formation of -ità derivatives: cinico 'cynic' $\rightarrow$ cinismo 'cynism' / ??cinicità, patriottico 'patriotic' $\rightarrow$ patriottismo 'patriotism'/??patriotticità, etc. Although Rainer maintains that this should be interpreted as a case of Paul's blocking, the high productivity of the two WFRs might be regarded as a clue that indeed an intertwining of the two types of blocking is going on here, because the frequency of the single derivatives cannot be kept totally distinct from the availability of the two synonymic WFRs expressed by productivity. The latter is in fact related to frequency (see the article 48 on productivity). In other words, a productive WFR can be blocked by the intervention of another productive WFR forming more frequent derivatives. 


\section{Domain-specific restrictions}

Let us now turn to specific restrictions relating to the different levels of linguistic analysis which have been pointed out in the literature. The discussion will be in some cases brief because several issues have been already touched upon in the foregoing sections.

\subsection{Phonological restrictions}

Besides the constraint on haplology mentioned above in section 2.2, there are generally three types of restrictions of a phonological nature. First, there may be selectional restrictions of a positive or a negative value relating to the segmental make-up of the base. For instance, a certain stem ending or the occurrence of certain segments within a stem may favor or hinder the combination with a certain suffix: respectively, the suffix -eer preferably selects bases ending with a dental voiceless obstruent: musketeer, profiteer, etc. (cf. Rainer 2005a: 344), while the Dutch noun-forming suffix -te as in koelte "coolness' cannot be added to adjectives ending in a vowel (cf. Bauer 2001: 129). More complex and much discussed especially from the viewpoint of an autosegmental approach to phonology is the case of the Latin suffix - àlis in capitālis 'capital', nāvēalis 'naval', etc., which takes the form -āris if the base contains a lateral: lünāris/*lūnālis 'lunar' (cf. Cser 2010). Notice that prefixes are generally held to be far less sensitive to base-driven phonological restrictions (cf. Rainer 2000: 881).

Second, the selectional restrictions may relate to the prosodic shape of the base; in particular word stress may play a role guiding, for instance, the positive selection of the suffix -al with regard to verbs stressed on the final syllable: arrival, rebuttal, etc. On the other hand, this restriction might also be seen as due to the preference for Latinate prefix-root verbs, which all happen to have final stress (cf. Malicka-Kleparska 1992: 437). Word stress is relevant for the derivation of circumfixal abstract nouns in German, insofar as only bases displaying initial stress are possible: klatschen 'to clap' $\rightarrow$ Geklatsche 'clapping' but applaudieren 'to clap' $\rightarrow$ *Geapplaudiere, etc. Third, the length of the base computed in syllables may be relevant, as in the suffix $-\mathrm{C}_{1}$ oj '-ish' found in the Mayan language Tz'utujil spoken in Guatemala, which only selects monosyllabic adjectives rax-roj 'greenish', q'eq-q'oj 'blackish' (cf. Bauer 2001: 129). The stress position and the syllable number may also form a joint restriction as in the case of the suffix -eer mentioned above which preferably selects bisyllabic trochaic bases: cameleer vs. * giraffeer, profiteer vs. *gaineer, racketeer vs. *fraudeer, etc. (cf. Rainer 2005a: 344).

\subsection{Morphological restrictions}

We have already seen some examples of morphological restrictions above when stratal constraints were discussed. In general, three types of morphology-driven restrictions can be determined. First, the base can belong to a class which is morphologically welldefined by means of stratal constraints or some other morphological feature like gender 
as in the case of the Hebrew sarcastic diminutive of the form $\mathrm{CCaCCaC}$ which can only be made from masculine nouns: zakan 'beard' $\rightarrow$ zkankan 'little beard' (cf. Bauer 2001: 130). In this regard, the reference to "etymological" information such as "of foreign origin" and the like mentioned in section 2.3 above might also be labeled as morphological (or lexical, possibly) because "most speakers do not have in their mental lexicons information about the sources of the words they use" (Bauer 2001: 130). Rather, the latter "are perceived as belonging to various synchronic classes" which "mimic etymological provenance (because that is their origin), but the mental listing involves assigning them to classes which are as random as (perhaps more random than) gender classes" (Bauer 2001: 131). In fact, we have also seen above that the etymological categorization often 'leaks', insofar as words of a wrong etymological type are included. Notice incidentally that reference to some information on the base, including when the latter already contains an affix, comes into conflict with those approaches which are typically represented by Anderson's (1992) "a-morphous morphology", because they surmise that a process of bracketing erasure cancels any morphological information contained in the base which is therefore inaccessible to further WFRs. This view is too radical, as shown by the highly productive selectional solidarity of -ize and -ation which does not hold when the ending has no morphological status: to realize $\rightarrow$ realization, but to surmise $\rightarrow{ }^{*}$ surmisation, etc. (cf. Rainer 2005a: 345).

Second, the base may have to show a particular morphological structure. In this regard, examples are found in which an affix only applies to complex bases, as the Punjabi prefix gair- 'un-', which only selects derived bases, e.g., deriving gairsarkaarii 'non-governmental' from sarkaarii 'governmental', itself derived from sarkaar 'government' (cf. Bauer 2001: 131).

The third possible case of morphological restrictions relates to the presence or the absence of a particular affix in the base, as in the case of the Dutch female suffix -ster which requires the presence of the suffix -aard '-er' in the base: wandelaarster 'female hiker' (cf. Bauer 2001: 131), or, conversely, the German suffix -heit which can be combined with compounds (e.g. Schreib-faul-heit 'the quality of being a bad correspondent, lit. write-lazy-ness'), prefixed adjectives (un-gleich 'un-equal' $\rightarrow$ Ungleichheit 'inequality') or circumfixed past participles (ge-schloss-en 'closed' $\rightarrow$ Geschlossenheit 'closure'), but does not generally apply to already suffixed bases as shown by freund-lich 'friend-ly' $\rightarrow$ *Freundlichheit/Freundlichkeit 'friendliness', ein-sam 'lonely' $\rightarrow$ *Einsamheit/Einsamkeit 'loneliness', in which the allomorph -keit has to be selected (cf. Aronoff and Fuhrhop 2002: 459), although sparse exceptions like blei-ern 'lead-en' $\rightarrow$ Bleiernheit 'leaden-ness' are attested. A positive correlation can give rise to the phenomenon of potentiation when the productivity of an affix is reinforced by the productivity of the affix in the base (cf. Williams 1981: 250). On the other hand, a negative correlation has been referred to in terms of closing morphemes, namely morphemes that "'close' the construction to other morphemes" (Nida 1949: 85, cf. van Marle 1985: 234-238 for Dutch, and Aronoff and Fuhrhop 2002 for German). The closing property is considered an idiosyncratic feature of the single affixes which has the effect of pre-empting the application domain of another affix, as for instance in the case of the Bulgarian suffix $-s k i$ forming denominal adjectives like pisatel 'writer' $\rightarrow$ pisatelski 'writer's' which cannot be further derived unless they are recent Russian borrowings like rus-sk-ost 'Russian-like style', svet-sk-ost 'worldly-minded style', etc. (see the article 55 on closing suffixes for a detailed discussion). 


\subsection{Syntactic restrictions}

Although at first sight one might expect to observe a number of clear-cut restrictions resulting from the interaction of morphology and syntax, in practice this turns out to "be more illusory than real" (Bauer 2001: 133). The often mentioned importance of the syntactic category of the base as a milestone for the WFRs has been overestimated, as pointed by several authors (see for instance Plank 1981: 43-45), while Plag (1998: 237) even dismisses it as "a by-product of the semantics of the process". More in general, allegedly syntactic restrictions can be always reinterpreted as morphological (or possibly lexical) in nature because of the way in which "a word is used depends to some extent upon the class it belongs to" and therefore "it might seem preferable to merge these two" (Bauer 2001: 133). However, in a more loose parlance one may treat under the label of syntactic restrictions those instances which refer to abstract properties of the bases which have an immediate effect on their syntactic behavior. One such case is represented by examples in which the argument structure of the verbal base is involved as suggested by the so-called "constructional" approaches to argument structure according to which "meaning resides in the syntactic context" (cf. Levin and Rappaport Hovav 2005: 18). For instance, it has been repeatedly claimed that the suffix -able normally combines only with transitive verbs: visitable vs. *goable, observable vs. *lookable, etc. On the other hand, depending on the theory transitivity has also be seen as a semantic, not a syntactic feature (cf. Rainer 2005a: 348). Similarly, in Apalai, a Cariban language spoken in Brazil, two different suffixes are used to form agent nouns, -ne with transitive and -kety with intransitive verbs (cf. Bauer 2001: 133): parata wo-ne 'rubber cutt-er' and wa-kety 'danc-er'. Finally, a particular tricky example is provided by the Australian language Diyari in which the attributive suffix -kanti i is used on "the set of common nouns which take the inchoative verbalizer and appear in the ergative case when used predicatively" (Austin 1981: 39) as in yudu 'power' $\rightarrow$ yudukantfi 'powerful one'.

\subsection{Lexical restrictions}

Since the role of the lexicon is ubiquitous in word-formation, it is difficult to identify genuinely lexical restrictions. One might conceive of two different sources for lexical restrictions. First, considering that unproductive WFRs normally give rise to shorter or longer lists of words in our mental lexicon, these lists have been generally assumed to form the lexical restrictions of the WFRs. Particular blatant are those cases in which the domain of a WFR is restricted to one or two single entries, as in bishopric, the only English word testifying of a suffix -ric, or laughter and slaughter which testify of the suffix -ter. Similarly, in Punjabi the nominalizing suffix -aapaa is found only in the noun kutaapaa 'beating' from the verb kutt 'to beat', and in Abkhaz the intensifier -samsal appears only in the adjective ày $k^{\circ} a c^{\circ}$ ' $a$-samsal 'very black' (Bauer 2001: 135).

Second, lexical restrictions may relate to class properties of the bases which have to do with their status within our mental lexicon. One example is given by the stratal conditions repeatedly discussed above, which can also be treated as lexical in nature if one thinks that they refer to the architecture of our mental lexicon rather than to formspecific properties of the words. A similar conclusion can also be reached if a "projec- 
tionist" approach to argument structure is adopted, which maintains that the latter results from the projection onto syntax of lexically specified information contained in the verb (cf. Levin and Rappaport Hovav 2005: 18).

\subsection{Semantic restrictions}

Similarly to the lexicon, also the role of semantics is ubiquitous because any WFR displays a meaning side which selects portions of the lexicon on the basis of their content. In this light, since a projectionist approach to argument structure may also be interpreted as involving a semantic restriction on the possible input, this would subsume under semantics all the examples discussed above.

In general, semantic restrictions are invoked when highly specific meaning aspects of the base domain are required in order to delimit the input of a WFR. For instance, the Italian suffix -eto combines only with plant or fruit names and forms nouns referring to the corresponding grove: canna 'reed' $\rightarrow$ canneto 'grove of reeds', arancia 'orange' $\rightarrow$ aranceto 'orange grove', etc. Similarly, in the Australian language Mangarayi the

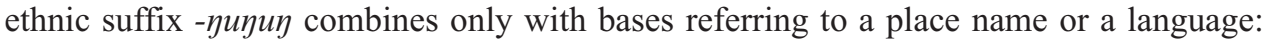

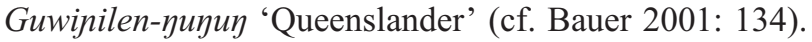

A certain debate has been animated by the question of the boundary between word meaning and world knowledge insofar as this is relevant for WFRs. For instance, the reversative prefix $u n$ - can only be applied to verbal bases displaying a reversible meaning: to unfold, to unscrew vs. to *unswim, to *unkill. While for the unacceptability of unswim a true semantic restriction may be invoked because the atelic process of swimming cannot give rise to any reversative interpretation, the unacceptability of unkill might be due to our encyclopedic knowledge which tells us that death is an irreversible state. The latter condition, however, might not hold in other possible worlds: for instance in the jargon of video-game aficionados unkill is a possible verb consisting in bringing back to life a character.

\subsection{Pragmatic restrictions}

As briefly hinted at in the previous section, a lively debate has focused on the possible distinction of the word meaning from our encyclopedic knowledge which is necessary in order to correctly understand "the nature of the real-world referent of the word" (Bauer 2001: 135) when it is used in a certain context. The latter perspective can also open the door for investigating the role of pragmatically-oriented restrictions on WFRs. For instance, the Dyirbal suffix -ginay meaning 'covered with, full of' is normally restricted to bases denoting something dirty or unpleasant as in gunaginay 'covered with faeces'. Similarly, in Kusaie, an Austronesian language spoken in Micronesia, the inchoative suffix -yak combines typically with names of insects (with the meaning 'to become infested with') or diseases (with the meaning 'to be badly affected by'). In Kannada, the adverbializing suffix -va:ra is generally restricted to a bureaucratic language, as in ko:mu-va:ra 'community-wise' (Bauer 2001: 135 and further references there). This reminds us of the German suffix -ität seen in section 2.4. above, which is sensitive to 
the stylistic register in which the base is employed. A full-fledged system of restrictions relating to stylistic-sociolinguistic features is provided by the Javanese "cromification" rules (cf. Becker 1990: 20-23).

Finally, restrictions of an "aesthetic" nature have been invoked for the speakers" refusal of certain words which are theoretically well-formed: for instance, Guilbert (1975: 191) discusses an aesthetic reaction against very long word in French as the reason preventing the formation of the adverb *oppositionellement 'oppositionally' from its base oppositionel 'oppositional'. In this vein, a merely aesthetic reason might be made responsible for the haplological blocking of * sillily in English. However, in the absence of solid investigations these observations have an impressionistic flavor.

\section{References}

Anderson, Stephen R.

1992 A-Morphous Morphology. Cambridge: Cambridge University Press.

Aronoff, Mark

1976 Word-Formation in Generative Grammar. Cambridge, Mass.: MIT Press.

Aronoff, Mark

1994 Morphology by Itself. Cambridge, Mass.: MIT Press.

Aronoff, Mark and Nanna Fuhrhop

2002 Restricting suffix combinations in German and English: Closing suffixes and the monosuffix constraint. Natural Language and Linguistic Theory 20: 451-490.

Austin, Peter

1981 A Grammar of Diyari, South Australia. Cambridge: Cambridge University Press.

Baayen, Harald and Robert Schreuder

2003 Morphological Structure in Language Processing. Berlin/New York: Mouton de Gruyter. Barri, Nimrod

1977 Giving up word formation in structural linguistics. Folia Linguistica 11: 13-37.

Bauer, Laurie

1983 English Word-formation. Cambridge: Cambridge University Press.

Bauer, Laurie

2001 Morphological Productivity. Cambridge: Cambridge University Press.

Bauer, Laurie

2005 Productivity: Theories. In: Pavol Štekauer and Rochelle Lieber (eds.), Handbook of Word-Formation, 315-334. Dordrecht: Springer.

Becker, Thomas

1990 Analogie und morphologische Theorie. München: Fink.

Carstairs, Andrew

1988 Some implications of phonologically conditioned suppletion. In: Geert Booij and Jaap van Marle (eds.), Yearbook of Morphology 1988, 67-94. Dordrecht: Kluwer.

Cser, András

2010 The -alis/-aris allomorphy revisited. In: Franz Rainer, Wolfgang U. Dressler, Dieter Kastovsky and Hans Christian Luschützky (eds.), Variation and Change in Morphology. Selected Papers from the $13^{\text {th }}$ International Morphology Meeting, Vienna, February 2008, 33-51. Amsterdam/Philadelphia: Benjamins.

Drapeau, Lynn

1980 Le rôle des racines en morphologie dérivationnelle. Recherches Linguistiques à Montréal 14: 299-326. 
Fabb, Nigel

1988 English suffixation is constrained only by selectional restrictions. Natural Language and Linguistic Theory 6: 527-539.

Gaeta, Livio

2006 The Lexical Integrity Principle as a Constructional Strategy. Lingue e Linguaggio 5(1): $1-16$.

Giegerich, Heinz J.

2001 Synonymy blocking and the Elsewhere Condition: Lexical morphology and the speaker. Transactions of the Philological Society 99: 65-98.

Guilbert, Louis

1975 La créativité linguistique. Paris: Larousse.

Gyurko, Lanin A.

1971 Affixal Negation in Spanish. Romance Philology 25(2): 225-239.

Haspelmath, Martin

2002 Understanding Morphology. London: Arnold.

Hay, Jennifer

2000 Causes and consequences of word structure. PhD. Dissertation. Northwestern University. Hay, Jennifer

2002 From speech perception to morphology: Affix-ordering revisited. Language 78: 527555.

Hay, Jennifer and Ingo Plag

2004 What constrains possible suffix combinations? On the interaction of grammatical and processing restrictions in derivational morphology. Natural Language and Linguistic Theory 22: 565-596.

Kiparsky, Paul

1973 "Elsewhere" in phonology. In: Stephen R. Anderson and Paul Kiparsky (eds.), A Festschrift for Morris Halle, 93-106. New York: Holt, Rinehart and Winston.

Kiparsky, Paul

1982 Lexical morphology and phonology. In: In-Seok Yang (ed.), Linguistics in the Morning Calm, 3-91. Seoul: Hanshin.

Klos, Verena

2011 Komposition und Kompositionalität. Möglichkeiten und Grenzen der semantischen Dekodierung von Substantivkomposita. Berlin/New York: Walter de Gruyter.

Levin, Beth and Malka Rappaport Hovav

2005 Argument Realization. Cambridge: Cambridge University Press.

Loporcaro, Michele

2012 Stems, endings and inflectional classes in Logudorese verb morphology. Lingue e linguaggio 11(1): 5-34.

Malicka-Kleparska, Anna

1992 Against phonological conditioning of WFRs. In: Jacek Fisiak and Stanislaw Puppel (eds.), Phonological Investigations, 423-442. Amsterdam/Philadelphia: Benjamins.

Marle, Jaap van

1985 On the Paradigmatic Dimension of Morphological Productivity. Dordrecht: Foris.

Nida, Eugene A.

1949 Morphology. The descriptive analysis of words. Ann Arbor: University of Michigan Press.

Paul, Hermann

1896 Über die Aufgaben der Wortbildungslehre. Sitzungsberichte der königlichen bayerischen Akademie der Wissenschaften, philosophisch-philologische und historische Classe, 696-

713 [Reprinted in: Leonhard Lipka and Hartmut Günther (eds.), Wortbildung, 17-35. Darmstadt: Wissenschaftliche Buchgesellschaft, 1981]. 
Plag, Ingo

1998 The polysemy of -ize derivatives: On the role of semantics in word-formation. In: Geert Booij and Jaap van Marle (eds.), Yearbook of Morphology 1997, 219-242. Dordrecht: Kluwer.

Plag, Ingo

1999 Morphological Productivity. Structural Constraints in English Derivation. Berlin/New York: Mouton de Gruyter.

Plank, Frans

1981 Morphologische (Ir-)Regularitäten. Tübingen: Narr.

Rainer, Franz

1988 Towards a theory of blocking: The case of Italian and German quality nouns. In: Geert Booij and Jaap van Marle (eds.), Yearbook of Morphology 1988, 155-185. Dordrecht: Foris.

Rainer, Franz

1993 Spanische Wortbildungslehre. Tübingen: Niemeyer.

Rainer, Franz

2000 Produktivitätsbeschränkungen. In: Geert Booij, Christian Lehmann and Joachim Mugdan (eds.), Morphology. An International Handbook on Inflection and Word-Formation,

Rainer, Franz vol. 1, 877-885. Berlin/New York: Mouton de Gruyter.

2001 Compositionality and paradigmatically determined allomorphy in Italian word-formation. In: Chris Schaner-Wolles, John Rennison and Friedrich Neubarth (eds.), Naturally! Linguistic studies in honour of Wolfgang Ulrich Dressler presented on the occasion of

Rainer, Franz his $60^{\text {th }}$ birthday, 383-392. Torino: Rosenberg \& Sellier.

2005a Constraints on productivity. In: Pavol Štekauer and Rochelle Lieber (eds.), Handbook

Rainer, Franz of Word-Formation, 335-352. Dordrecht: Springer.

2005b Semantic change in word formation. Linguistics 43(2): 414-441.

Rainer, Franz

2012 Morphological metaphysics: virtual, potential, and actual words. Word Structure 5: 165182.

Saciuk, Bohdan

1969 The stratal division of the lexicon. Papers in Linguistics 1: 464-532.

Scalise, Sergio

1984 Generative Morphology. Dordrecht: Foris.

Schwarze, Christian

1970 Suppletion und Alternanz im Französischen. Linguistische Berichte 6: 21-34.

Siegel, Dorothy

1977 The Adjacency Condition and the theory of morphology. In: Mark J. Stein (ed.), Proceedings of the Eighth Annual Meeting of the North East Linguistic Society, 189-197. Amherst, Mass.

Siegel, Dorothy

1979 Topics in English Morphology. New York: Garland.

Spencer, Andrew

1988 Bracketing paradoxes and the English lexicon. Language 64: 663-682.

Stump, Gregory T.

2001 Inflectional Morphology: A Theory of Paradigm Structure. Cambridge: Cambridge University Press.

Williams, Edwin

1981 Argument structure and Morphology. The Linguistic Review 1: 81-114. 